\title{
Petite ou grande mort? A sexualidade e o imaginário tecnológico contemporâneo ${ }^{1}$
}

\author{
Juliana Tonin² \\ PUC-RS \\ jutonin@terra.com.br \\ Barbara Nickel3 \\ PUC-RS \\ barbaranickel@terra.com.br
}

\begin{abstract}
Resumo: Este artigo discute algumas implicações contidas nas novas relações sexuais estabelecidas através das ou com as máquinas. Através da discussão do imaginário tecnológico, tal como ele pode ser observado nos filmes O Passageiro do Futuro e Inteligência Artificial e parece se apresentar em práticas contemporâneas, especula-se acerca de um erotismo diferente daquele pensado por Bataille. Nesse novo, subjaz um desejo de eliminação do outro que é, no limite, de si próprio.
\end{abstract}

Palavras-Chave: 1. sexo 2. imaginário tecnológico 3. alteridade

Resumen: Este artículo discute algunas implicaciones contenidas en las nuevas relaciones sexuales establecidas por medio de o con las máquinas. A través de la discusión del imaginario tecnológico, tal como se puede observar en las películas The Lawnmower Man e Inteligencia Artificial, y como parece presentarse en prácticas contemporáneas, se especula acerca de un erotismo diferente de aquél pensado por Bataille. En este nuevo erotismo, subyace un deseo de eliminación del otro que es, al final, el deseo de eliminarse a si mismo.

Claves: 1. sexo 2. imaginario tecnológico 3. alteridad

\footnotetext{
${ }^{1}$ Trabalho apresentado ao Grupo de Trabalho "Tecnologias Informacionais de Comunicação e Sociedade", do XV Encontro da Compós, na Unesp, Bauru, SP, em junho de 2006. Este artigo é um aprofundamento de idéias iniciais lançadas no texto intitulado "Sexo Ciborgue: uma união inusitada entre o desejo da carne e a racionalidade cibernética" apresentado no Seminário Internacional da Comunicação, na PUCRS, em novembro de 2005. 2 Doutoranda do PPGCOM da PUCRS. E-mail: jutonin@terra.com.br 3 Mestranda do PPGCOM da PUCRS. E-mail: barbaranickel@terra.com.br
} 


\begin{abstract}
This article examines some implications contained in the new sexual relations established through the machines or with them. Through the discussion over the technological imaginary, as it can be observed in the movies The Lawnmower Man and Artificial Intelligence, and that it seems to presents itself in contemporary practices, this paper conjectures about an eroticism that would be different from that imagined by Bataille. In this new eroticism, underlies a will of the elimination of the other, which is, in the limit, a will of elimination of oneself.
\end{abstract}

Keywords: 1. sex; 2. technological imaginary; 3. otherness.

Résumé: Cet article discute quelques implications présentes dans les nouvelles relations sexuelles établies à travers ou avec des machines. À travers la discussion de l'imaginaire technologique, telle q'elle peut être observée dans les films Le Passager du Futur et L'Intelligence Artificielle et comme elle semble se présenter dans des pratiques contemporaines, il est possible de considérer l'existance d'un erotisme différente de celui pensé par Bataille. Dans ce nouveau concept repose un désir d'élimination de l'autre qui est aussi, à la limite, le désir d'élimination de soi même.

Mots-clés: 1. sexe 2. imaginaire technologique 3. altérité

Repúdio e culto ao corpo ganham, na cultura contemporânea, novas dimensões. O imaginário tecnológico parece sustentar projetos de intensificação, ou diversificação, de prazeres sensuais; ao mesmo tempo em que suporta desejos de desmaterialização ou descorporificação. O ponto, que soa paradoxal, tem alimentado discussões a partir de perspectivas variadas ${ }^{4}$. Claudia Springer (1996) já o notou nos discursos relativos à conexão entre sexualidade e tecnologia, percebendo que, se eles desprezam o corpo como carne e anseiam por uma transcendência informacional, também incluem nesse cenário uma plena, e até amplificada, satisfação dos desejos sexuais.

\footnotetext{
4 FELINTO, Erick. O corpo impuro: sobre a digitalização da matéria no imaginário da cibercultura. In: Encontro Nacional da Associação Nacional dos Programas de PósGraduação em Comunicação, 13, 2004, São Bernardo do Campo. Anais... São Bernardo do Campo, 2004. Disponível em: http://www.comunica.unisinos.br/tics/?page=textos2004. (Último acesso em: 15/9/2005.) SIBILIA, Paula. O bisturi de sotware: ou como fazer um "corpo belo" virtualizando a carne impura? In: Encontro Nacional da Associação Nacional dos Programas de PósGraduação em Comunicação, 14, 2005, Niterói. Anais... Niterói, 2005. Disponível em: http://www.comunica.unisinos.br/tics/?page=textos2005. (Último acesso em: 15/9/2005.)
} 
É nesse contexto que se pretende pensar uma dimensão do imaginário atual, aquela que diz respeito às possibilidades de transformações nas relações sexuais intermediadas pelos novos dispositivos tecnológicos. Tenta-se observar que a vontade manifesta nesse tipo de relação é, na realidade, uma vontade de eliminação do outro. Não apenas o outro que pode transmitir doenças ou escancarar a fragilidade da carne, como ressalta Springer, mas também o outro que carrega consigo o inesperado e que pode não responder de acordo com as expectativas.

Pensa-se, assim como David Le Breton, que "no sexo cibernético, o outro não existe" (2003, p. 177), mas aqui procura-se explorar essa noção de maneira mais radical. O autor preocupa-se especialmente com o desaparecimento do corpo nessas relações. Este texto, por outro lado, especula sobre a possibilidade deste desaparecimento ser uma dimensão do imaginário de superação da humanidade. Uma expressão da vontade de, no limite, eliminar-se a si próprio.

Georges Bataille (1987) pensa que uma relação erótica é momento de crise, um instante em que o indivíduo rompe com a sua estrutura de ser fechado e vive através do seu objeto de paixão (o Outro) uma experiência fora si, fora do Eu. O ser se desnuda, se despoja da posse individual, se entrega à mais intensa e insignificante crise. Ele se perde objetivamente, o Eu se perde, mas se identifica com o objeto em que se perde. No momento da fusão o ser se entrega a uma experiência de morte, seu Eu deixa de existir. Enquanto o corpo, isolado, pode significar uma espécie de servidão diante das coisas, num ato sexual este valor se inverte, ele, em sua animalidade, torna-se divino, poético. As formas dos amantes não desaparecem pelo ato, isso seria a morte dos mesmos, mas são perturbadas ao máximo. Experimentam uma petite mort. O sexo, segundo este ponto de vista, é uma experiência interior do Eu através do Outro.

O que permite a fusão de corpos, a atração de um indivíduo por Outro, é o desejo. $\mathrm{O}$ autor esclarece que este mantém o homem em vida e não o leva a extremos por ceder à morte ou à própria violência do desejo. "De duas coisas uma, o desejo nos consumirá, ou seu objeto cessará de nos queimar". Assim é que o homem busca seu objeto sob a condição de que o desejo se acalme com o tempo. Para ele, afirma Bataille, é preferível a morte do desejo à própria morte. Por isso, acaba se satisfazendo com ilusões, uma delas é a de possuir o objeto sem morrer, mas dando 
fim ao desejo. "Nós renunciamos a morrer; anexamos o objeto ao desejo que era, na verdade, o de morrer; nós o anexamos à nossa vida durável. Enriquecemos nossa vida em vez de perdê-la” (1987, p. 133).

Através das proposições de diversos autores, mas especialmente Jean Baudrillard e Lucien Sfez, este texto parte para a especulação de que este tempo pretende, através dos avanços científicos e tecnológicos, a eliminação do Outro, numa fantasia de assepsia social, de prevenção contra todas as impurezas que são entendidas como negatividades das quais, uma vez livres, homens imunes e perfeitos podem emergir. Bataille pensou que o desejo de um objeto substituía o desejo e a morte, mas hoje também se pode especular que o desejo de pureza e perfeição elimina o objeto. Este, como condição fantástica para permanecer durável, se quer abolido. O homem teria renunciado à ilusão e cedido à vontade de morte? As novas configurações do ato sexual seriam um indício.

Essas novas relações são aquelas virtuais, através de telas de computadores ou em ambientes de simulação, e ainda podem abarcar outros tipos, que se dêem através de outros aparatos tecnológicos. Podemos observá-las em chats ou sofwares eróticos, em que o prazer é estimulado a partir da interação com uma máquina que responde às informações enviadas pelo usuário. Em um jogo, é a tela do computador que reage às decisões de tirar esta ou aquela peça de roupa de alguma personagem; ou de modificar a posição em que ela se encontra. Num chat, a resposta também se dá de acordo com aquelas informações disponibilizadas pelo participante que, insatisfeito, pode decidir interromper a ação em curso, desligar a máquina e ir embora, ou simplesmente trocar de parceiro. Ele pode assumir qualquer identidade e esperar, a partir do personagem criado, as respostas desejadas.

Há também quem se utilize de sofisticados mecanismos de estímulo a partes íntimas, em uma espécie de contato à distância, vivenciada através de roupas ou vibradores passíveis de serem acionados por um usuário ao qual se esteja conectado pela rede. Nesse caso, a experiência é menos cerebral e mais corpórea do que aquela registrada nos chats ou jogos virtuais. Aqui, é possível que um dos participantes informe ao outro qual é o seu desejo, a medida que este responde acionando esta ou aquela função do aparelho ligado ao corpo de seu parceiro. 
Ao discutir as novas possibilidades de relação entre corpo e dispositivos tecnológicos, Francisco Coelho dos Santos defende que "resta sempre a convicção de que o mais importante na sexualidade passa ao largo da mera estimulação mecânica, mesmo quando ela tem origem na atividade de um(a) outro(a)" (2003, online). Esse outro, na relação erótica concebida por Bataille, não é simplesmente o que estimula, mas é também aquele a quem o parceiro se desnuda, se entrega, em quem ele se perde. O status desse outro, portanto, é diferente quando o ato sexual exige uma mediação de uma máquina ou até mesmo permite a substituição do parceiro por uma máquina. O que está em jogo nessas novas relações são outras demandas, são expressões de uma outra ordem - capazes de revelar algumas dimensões do imaginário contemporâneo.

Elas expressam uma busca por um sexo perfeito, sem as incomodações e imprevistos naturais das relações humanas. A pureza, o bem, a assepsia, a segurança, ideais de perfeição a serem atingidos pela técnica. Mas busca não é conquista e cabe lembrar que essas aspirações refletem a situação vivida concretamente e são refletidas nelas, mas não correspondem a elas. A perfeição é a fantasia, que, mesmo por vias e com objetivos diferentes, é constatada tanto por Sfez quanto por Baudrillard.

Para Sfez (1996), ela é o mito da nossa época e ele a chama de Grande Saúde. Ela é manifesta, segundo ele, nos projetos utópicos que dão suporte à idéia de ser possível construir um mundo perfeito para os seres humanos através do desenvolvimento tecnológico. O objetivo é a eliminação da doença, da morte, do mal, enfim, daquilo que nos faz vulneráveis e que é, enfim, a alteridade. "O outro é sempre perigoso. Como o outro em nós, o incontrolado" (p. 313). A Grande Saúde tem o respaldo da ciência e se dissemina através do discurso dos "homens de laboratório", amplificado por comentadores. Enquanto ela reina, segue-se tentando promover a limpeza do planeta, da sociedade e do homem, transformando-o, afinal, em um ser translúcido. "O corpo esportivo, não atingido pelos vírus, não misturado a outros em paixões malsãs, não entorpecido por gorduras ruins, não programado por genes defeituosos, deve permanecer puro. Pureza nobre de uma saúde perfeita" (SFEZ, 1996, p. 64). 
O desenvolvimento tecnológico, pensa Baudrillard, é a tradução de um homem que deixou de acreditar na própria existência e optou por uma existência virtual, um destino por procuração. O projeto tecnológico não pretende uma transformação no mundo, mas a criação de um mundo autônomo, plenamente realizado, do qual o homem possa se retirar. Para a conquista da imunidade total, da imortalidade, é preciso retirar as imperfeições do mundo natural e do homem, praticar a perfeição, produzir tudo como artefato, criar o artefato homem, livre para uma gravitação eterna numa órbita artificial. E o discurso da ciência e do progresso move o homem numa aceitação cada vez maior da técnica como produtora de um ambiente artificial funcionando como uma segunda natureza através do argumento da mais pura lógica da espécie, a evolução. Para ele o que se pretende é operar uma cirurgia estética do negativo. "Realiza-se o mundo, faz-se existir e significar a qualquer preço, é-lhe retirado todo o caráter secreto, arbitrário, acidental, são expulsas as aparências em proveito do sentido, da eficácia máxima, o mundo é arrancado de sua forma para ser devolvido em sua fórmula" (1996, p. 27-39). Toda a determinação natural é transformada numa fórmula operacional, é a operação cirúrgica do mundo real.

As novas configurações do sexo são uma expressão dessa transformação. As fantasias despertadas pelas possibilidades concretas podem ser vistas de forma radicalizada em produções culturais, como o cinema. Se é possível pensar exemplos de novas relações sexuais através ficção, deve-se considerar que toda ficção provém de um imaginário que alimenta e é alimentado pela realidade. Como escreve Machado da Silva: “(...) pode-se dizer que o imaginário tecnológico é o produto de um imaginário social, socialmente imaginado e construído, que condiciona em ricochete, conforme as tecnologias do imaginário disponíveis em determinado momento" (1999, p. 133).

Todas as transformações do real que interferem no imaginário e acabam tornando possíveis estas criações, bem como condicionamentos que levam o homem a adotar comportamentos, são consideradas aqui, reflexivamente, como uma tentativa de eliminação do homem, mesmo se as explicações racionais e cotidianas insiram-se numa lógica evolutiva da espécie humana, numa necessidade de 
entendimento de que o único obstáculo à plenitude humana é o desconhecimento de si, suas falhas constantes, seus germes, suas impurezas, tudo o que o faz degenerar.

Duas cenas de filmes, que parecem emblemáticas das fantasias atuais de possibilidades de se obter prazer sexual através de novos dispositivos tecnológicos, podem servir de suporte para compreender o fim da alteridade nas relações sexuais. Uma é do filme Inteligência Artificial (2001), entre Gigolô Joe (Jude Law), um robôamante, e uma mulher de carne e osso; a outra é de O Passageiro do Futuro (1992), em que os personagens Jobe Smith (Jeff Fahey) e Marnie Burke (Jenny Wright) protagonizam uma relação em um ambiente de realidade virtual.

Gigolô Joe, o robô-amante, é criado para servir às mulheres de um sexo pensado perfeito, sem as dificuldades implicadas freqüentemente em uma relação entre humanos. Neste cenário futurista, robôs-amantes masculinos e femininos são produzidos em série. Eles são programados para satisfazer desejos e fantasias, seja por cumprimento de uma ordem ou por "leituras" do corpo do usuário, identificando, através de uma espécie de sensibilidade tecnológica, os melhores procedimentos a seguir com o objetivo de proporcionar prazer.

Na obra, o Gigolô e a mulher realizam uma fusão, uma relação que parte da solicitação da mulher por uma máquina, imitação de homem, com o qual ela possa praticar um sexo seguro, perfeito, limpo e satisfatório. Não operam mais o acaso, a paixão por um objeto e a luta para a conquista de um momento de fusão, de entrega a este objeto.

É como se nas prateleiras de um grande supermercado houvesse, entre as mercadorias mais variadas, de detergentes a pães, um produto que se promove dizendo: "nós trabalhamos sob você, em você e para você, não engravidamos, não precisamos ser apresentados aos pais, não precisamos que você se esforce ao máximo para sentir algum prazer, precisamos apenas que nos contrate (ou compre), que aceite uma representação de um humano além do que é humanamente possível, que aceite definitivamente os prazeres sem culpa. Você é um deus ou uma deusa, e é 
preciso ter, pelo menos na cama, alguém à sua altura5”. Os benefícios superam qualquer despesa.

No filme O Passageiro do Futuro, Jobe Smith e Marnie Burke vivem uma cena em que praticam sexo virtual. Os dois se conectam a máquinas e se encontram, diferentes de suas formas originais (humanas), numa outra dimensão. Eles, na fusão, visualizam-se num entrelaçamento que os transforma num único ser, uma libélula, que viaja através de um túnel até uma região na qual a personagem se separa do parceiro e fica presa numa substância gelatinosa. A relação, que antes prometia intensas sensações e a possibilidade de realizar e ser o que se quiser ser, acaba deixando Marnie perturbada. Sem saber o que fazer, seu desespero aumenta quando vê que seu parceiro está se transformando num inseto gigante prestes a devorá-la.

Seu medo talvez seja um reflexo do ineditismo da experiência, pois ela, imersa pela primeira vez nesse ambiente, não parece conseguir distinguir claramente a sua imagem virtual do seu corpo físico. Grudada na substância gelatinosa ou prestes a ser atacada pelo inseto, Marnie expressa temor pelo que pode lhe atingir como se aquilo fosse mais que um jogo, como se aquilo fosse, de fato, lhe trazer danos concretos. Ela não sabe o que está, na verdade, lhe acontecendo, e entra em pânico. Há uma tensão entre real e virtual que, enfim, acaba por aniquilar não apenas a sua imagem no jogo, mas também seu corpo fora dele. Jobe, que vem sendo treinado há bastante tempo em ambientes de realidade virtual, mantém-se calmo, sabendo que é uma espécie de jogo, até ouvir o alerta proveniente da estação de Marnie indicando enfraquecimento da atividade cerebral. Ele imediatamente desliga os aparelhos, mas é tarde demais. Ela está em estado de choque e ficará louca para sempre, como mostram as cenas seguintes do filme. O importante de se notar é que algo sai errado. Marnie deseja parar, pede para Jobe lhe ajudar a sair dali. Ele, porém, não tem controle, não pôde prever, tampouco pode impedir o acontecimento.

No filme Inteligência Artificial, há uma sensível resistência, por parte da mulher, para aceitação do parceiro Gigolô Joe, e depois o gozo de uma relação sexual entendida como perfeita. Por outro lado, o Passageiro do Futuro exprime um tipo de

\footnotetext{
5 Estas falas foram retiradas do filme e espetacularizadas para melhor ilustrar a função e promessa de um robô amante.
} 
relação na qual há uma imediata aceitação e uma conseqüência nefasta: a loucura de Marnie. A promessa de prazer através de dispositivos tecnológicos, cumprida no primeiro caso, é um ponto de tensionamento no segundo. Um indício de que a perfeição imaginada pode ser mais fantasiosa do que se apresenta: a possibilidade do inesperado sempre existe.

O que esse imaginário aponta é que se deseja, enfim, a eliminação das condições humanas do sexo: a imprevisibilidade, o desconhecimento do corpo do outro, o fato de se desnudar a ele, se abrir e se tornar passível de julgamento. Expor uma fragilidade até então oculta sob as vestes, abolir o fator determinante de participar tanto do prazer e da entrega do outro, como de si mesmo. Nos exemplos citados, ficcionais e reais, tem-se a vantagem de não ser necessário preocupar-se em acertar a música, o perfume, a roupa íntima, de não precisar lidar com odores, secreções e com o que é desconhecido, este outro irredutível.

Jean Baudrillard pensa que numa relação sexual, como se escreve aqui, através chats, dispositivos tecnológicos, softwares, o que está em jogo é uma grande faxina nos aspectos incômodos, incluindo o Outro. Acredita que o homem está contaminado por uma doença sexualmente transmissível, o sexo, ocasionando, assim, transformações, desapegos, afastamentos: “(...) tem-se medo de pegar qualquer coisa que se assemelhe à paixão, à sedução, à responsabilidade” (2002, p. 69). Antes as sociedades pensavam o incesto como algo trágico, agora, pelo entendimento do sexo como doença, os homens vivem o incesto transformado de sexual e familiar para cissíparo e protozoário, copulam consigo mesmo, sem passar pelo Outro (1990, p. 129). O sexo não seria mais uma relação dual, mas uma função reversível. Em vez de alteridade, uma corrente alternativa.

O outro, para Sfez, é o que se deseja eliminar através da Grande Saúde. O outro que está na doença, na poluição, no mundo de aleatoriedades fora de nosso controle. Que, nas novas formas de sexo, tenta-se reduzir ao máximo: sem contato físico direto, o corpo não se expõe a vírus ou organismos estranhos quaisquer que sejam; sem encontro, o indivíduo não se sujeita ao arrebatamento da paixão ou da decepção. Fica na segurança -na monotonia? - de si mesmo. Essa, ao menos, é a fantasia. Segundo pode-se depreender das observações do autor, esse ideal encontra ressonância especialmente dentro da visão de mundo norte-americana, cujos traços 
culturais parecem favorecer a distância entre as pessoas (onde "um olhar é um assédio").

Um robô-amante, tanto quanto uma relação conduzida em um ambiente virtual, então, satisfariam um instinto sexual sem exigir o contato entre os corpos, sem as turbulências características das relações entre pessoas. Como observa Sfez, "estas técnicas contribuem para a visão de uma sociedade perfeita, sem os conflitos devidos ao amor, sem o espírito de posse e de dominação das desordens sexuais, sem essa mistura escabrosa dos corpos" (1996, p. 315).

Para o sexo, então, a técnica parece ser o caminho na direção desse objetivo final. Nas relações sexuais através de chats, de outros aparatos tecnológicos disponíveis, bem como as pensadas através dos filmes citados, tem-se o sexo do mesmo com o mesmo - sou Eu que retorno através do estímulo emitido.

No sexo com o Gigolô Joe, não há nada além de si mesmo, pois se busca um robô-amante que terá como função apenas realizar o que o Eu quer, uma relação de estímulos que este ser deseja que sejam respondidos. Não há mais um outro para tolerar, impurezas para contaminar, são as próprias impurezas que se contaminam a si mesmas num ciclo sexual de vai-e-vem do mesmo ao mesmo. Ao relacionar-se com um robô, imagina-se que nada falhará: isso porque não existe, em tese, o outro, sempre capaz de surpreender. O sexo, ali, é uma relação da mulher consigo mesma, enfim. É com base em suas demandas que a relação será conduzida. A máquina está ali para suprir seus anseios, não para exigir satisfação. Se a relação ainda é física e corporal, não existe, entretanto, o corpo de um outro. O corpo segue existindo como terminação nervosa sensível ao prazer, de um lado - mas é apagado enquanto objeto de desejo, na concepção erótica de Bataille. Um robô-amante não é uma alteridade, é um recurso para a saciedade. Não há um Outro em que o Eu possa se perder. O Eu retorna a si.

A inexistência do outro, ressalte-se, é exatamente o argumento de defesa para um similar de Gigolô Joe, a andróide Hadaly da ficção A Eva Futura, tal como esta é apresentada por Sfez. Assume-se, nesta obra, que o ser amado não existe, de fato, jamais. É sempre uma ilusão, uma projeção dos desejos do amante. O cientista, 
no livro, tenta convencer seu amigo de que a boneca e a mulher podem ser amadas não pelas suas características intrínsecas, mas pela imaginação de quem ama.

- Mas como amar uma boneca científica, que não tem consciência de si mesma?

Resposta de Edison: esta consciência de si mesma só depende de vós. O ser que amais na viva, e que é para vós somente real, não é aquele que aparece nessa humana passageira, mas o de vosso desejo. Ou seja: no amor-paixão já se vive só com uma sombra. (...) Adeus, portanto, à pretensa Realidade, a antiga trapaceira, e tentemos a solução do artificial. (SFEZ, 1996, p. 15)

Le Breton, em seus comentários sobre o texto de Villiers de L'Isle Adam, também chama atenção ao fato de que a construção do andróide remete sempre a uma aniquilação do outro em favor da satisfação irrestrita dos desejos do usuário/proprietário deste tipo de recurso. Essa fantasia também sustenta um desprezo pelo corpo - na maioria das vezes, feminino. Ele afirma, por exemplo, que Pigmalião

Modela com suas próprias mãos seu ideal do outro feminino, maneira de amar a si mesmo ocultando a prova de alteridade que é necessariamente o enigma do corpo do outro, começando pelo seu rosto. Esse sonho de contornar o corpo com a máquina, de pouparse o medo do desnudamento, é encontrado em muitas narrativas da literatura ocidental (...) (2003, p.165).

Baudrillard pensa que, nas relações que se davam com os autômatos mecânicos (séc. XVIII), ainda era possível a interrogação e o charme da diferença entre homem e máquina. Com os interativos "homem e a máquina tornaram-se isomorfos e indiferentes, já ninguém é o outro do outro". Enquanto isso, técnicas de reprodução artificial (ou de criação de vida artificial) cuidam da continuidade da espécie no planeta - liberando os homens da necessidade de se misturarem para criar descendentes. "O ser interativo nasceu não de uma forma nova da troca, mas do desaparecimento do social e da alteridade. É o outro de depois da morte do Outro e que já não é absolutamente o mesmo. É o outro que resulta da recusa do Outro" (1990, pp. 131-133).

No sexo virtual, do filme O Passageiro do Futuro, a promessa é que se possa viver uma experiência que transcenda a forma do corpo e as possibilidades reais do sexo, pode-se viver a imaginação e o inimaginável do sexo. Mesmo que dois corpos 
estejam simulados ali, é preciso pensar que não há o contato com o outro e nem a certeza de que se possui um corpo físico. Nem as próprias impurezas e materialidades são sentidas no ato, pois o corpo não é tocado e não toca nada além do ar. De acordo com Le Breton, pode-se dizer que o corpo do outro não passa de local de conexão, para mais, é supérfluo (2003, p. 179).

O que está em jogo, neste caso, em se tratando de uma relação sexual, é uma sexualidade descorporificada. Como afirma, ironicamente, Le Breton, "eliminar concretamente o corpo da sexualidade é o melhor meio para deixá-lo sem condições de prejudicar a sexualidade" (2003, p.176). Considerando-se o filme como uma radicalização, uma visão mais sofisticada, dos recursos disponíveis à maioria das pessoas, já que a imersão mostrada na obra ainda não é popularizada e ainda se recorre com mais freqüência a chats, softwares ou mesmo dispositivos teleoperados, poder-se-ia afirmar, com auxílio de Lucien Sfez que

A cibercultura apaga o corpo e modela a percepção sensorial reduzida à vista, tal como o cibersexo apaga o desejo para reduzi-lo ao olhar. O poder do corpo é apagado, ao passo que só subsiste o movimento da mão que modifica a tela e proporciona ao indivíduo um sentimento de controle paradoxal, sem contato físico. (1996, p. 280)

No ambiente de realidade virtual, o digital apresenta-se como liberação dos obstáculos da realidade. É um espaço onde a mente, o cérebro, a consciência, valem mais que a imperfeita materialidade do corpo. Na contemporaneidade o corpo parece possuir outras atribuições, ao invés do lugar da alteridade, passa a ser da identificação, obrigando uma reconstrução, fazendo dele objeto ideal, segundo Baudrillard.

O corpo e o sexo, nessa dimensão digitalizada e descorporificada, assumem a forma desejada pelo usuário. Enfrentar a alteridade para quê, se é possível eliminar o incômodo, o desagradável, a incerteza de sucesso? A construção do corpo como objeto ideal, ou seja, puro, limpo, belo, agradável ao olhar - mas, é importante notar, não palpável - através dos recursos digitais, é vista por Paula Sibilia (2005) como uma "redefinição radical da sensualidade". Nessa nova, a carne é dispensada "em prol de uma pureza imagética". É uma expressão individual do mesmo imaginário tecnológico que, na relação sexual, deseja eliminar a impureza representada pela alteridade. 
Nas novas relações sexuais explícitas aqui há, primeiro, a eliminação do outro, ausente da relação. Seja pela consideração de que é supérfluo, substituível por um robô-amante, imperfeito em sua condição humana. Seja pela sua substituição por um aparato de realidade virtual que, em tese, deveria dar-lhe prazer através de imagens e impulsos elétricos, longe das impurezas da carne. Segundo, de si, pois a ausência do outro em que o eu possa se perder, a vontade de morte não tem a ilusão de se dissolver na aparente satisfação do desejo pelo objeto.

A idéia de que, numa relação erótica. o indivíduo, para iludir sua vontade de morte, fixa seu desejo num objeto e vive uma petite mort é defendida por Bataille. Como referido, este jogo seria a maneira que o homem encontra para permanecer durável. Esta relação, porém, foi pensada por ele como se um ser fosse objeto de outro ser, sem mediações. Através da adesão aos meios que (des)reconfiguram o momento da fusão entre os seres não parece possível atribuir o mesmo sentido ao ato sexual. Pois o que se perde não é mais o Eu, é o objeto de desejo, elimina-se o Outro, a alteridade irredutível. Aparentemente o que se vê é o nascimento de um Eu onipotente. Contudo, Rimbaud já o dissera: o Eu é um Outro. A conseqüência primeira de uma eliminação do Outro acarreta a própria desaparição, vitória da vontade de morte sobre o desejo do objeto.

Porém não se poderia atestar que a espécie humana teria aderido ao desejo de morrer. Através do imaginário tecnológico, não se manifesta como horizonte a ser atingido a morte, mas se projeta a superação. É nessa fantasia de superação, no entanto, que subjaz como conseqüência não a elevação do homem para uma condição suprema da existência, mas para uma condição absoluta da inexistência. Pode-se refletir, então, que a ilusão do objeto foi substituída pela ilusão de superação sem objeto, na qual a perda do próprio objeto acaba sendo menos ameaçadora do que a perda da duração.

Entre Baudrillard e Sfez existe o paradoxo de se estar num mundo no qual a ilusão é banida e a catástrofe instaurada para o primeiro, e de se estar vivendo uma utopia, um mito, nas mesmas atribuições simbólicas dadas aos outros mitos, somente com uma conseqüência fatal para o segundo. Paradoxo aparente, pois é possível afirmar que o fim da ilusão para Baudrillard é o início da ilusão radical para o Sfez. O homem teria eliminado o objeto para radicalizar a ilusão: rumo à idéia de evolução, 
tem-se a desaparição. Pois numa ilusão de um objeto, o homem é movido pelo desejo e aniquila-o. E numa ilusão radical, o homem é movido pela idéia e se aniquila.

Jean Baudrillard acredita ser necessário repensar McLuhan. Se este via nas tecnologias modernas "extensões do homem", é preciso antes ver nelas "exclusões do homem" (1996, p. 61). Infere ser diretamente proporcional o crescimento da cerebralidade das máquinas à purificação tecnológica dos corpos. Rumo à positividade total cumpre-se o projeto de desaparição da espécie, mascarado pela idéia de elevação.

Não é absurdo supor que a exterminação do homem comece pela exterminação de seus germes. Porque tal como é, com seus humores, paixões, riso, sexo, secreções, o homem não passa de um germezinho sujo, vírus irracional que perturba o universo da transparência (BAUDRILLARD, 1990, p. 68).

Seu desejo de retirar-se do processo de geração de descendentes, expresso na corrida das pesquisas de métodos artificiais de reprodução, é concomitante à busca de prazer sexual em conjunção com a tecnologia. O que é a clonagem senão um desejo de produção de uma descendência igual a si próprio, uma eliminação radical do outro? Ao lado dela, a fantasia de criação de uma forma de vida artificial - à imagem e semelhança do homem e para a qual ele seria uma espécie de deus. Se inúmeros discursos, filosóficos ou científicos, apontam para o fim do humano, os esforços atuais em projetos que visam ao fim do sexo humano, tal como se conhece hoje, não devem surpreender. A contemporaneidade seria como uma etapa na projeção de um destino, como escreve Sfez,

sem fortuidade, sem impureza, sem morte nem decomposição, sem poeiras nem corpos estranhos, sem jogos nem prazeres, e sem outra respiração que a que comanda o conjunto da grande maquinaria. Mundo, neste sentido, sobrenatural e que deve sua superioridade ao artifício (1996, p. 110).

As cenas exploradas de O Passageiro do Futuro e Inteligência Artificial permitem enfatizar a própria tensão de se estar prosseguindo, imaginando, desejando uma espécie de relação sexual que, mais que prescinde, acaba por aniquilar o homem. No primeiro, o ato se apresenta libertário, sem fronteiras, mas termina, inesperadamente, trágico. No segundo, o dispositivo tecnológico que é o andróide oferece e, ao que parece, concretiza uma experiência perfeita. De toda maneira, em 
ambos, o que se tem é a eliminação do homem. Não se afirma, aqui, que esse destino se concretizará ou não - apenas que o imaginário tecnológico contemporâneo sustenta produções culturais e práticas cotidianas, relativas ao campo sexual, que denunciam tais projetos. A vontade subjacente de eliminação do outro nas relações sexuais que se configuram a partir dos novos dispositivos tecnológicos expressa, portanto, em sua compreensão mais radical, a vontade de superação do homem, rumo a um destino livre da condição imperfeita, que é a sua.

O questionamento de Baudrillard "Não será que inventamos um meio altamente secreto de radicalizar a nossa existência dando-lhe uma possibilidade de desaparição total?” parece preciso. Ele faz pensar no homem como vítima e assassino de si. Um crime perfeito, por não deixar marcas e ser irreversível (BAUDRILLARD, 1996, p. 64). Uma perfeição criminosa, por conduzir à morte, ao fim, do homem. Uma fantasia de superação que, porém, exige o extermínio daquilo que viria a ser superado.

Se o software, o chat e o robô-amante colocam a técnica como garantia de um sexo perfeito, uma falha do Windows, uma falta de luz ou talvez o fim da bateria do andróide indicam o status fantasioso dessa perfeição. E esse imaginário contemporâneo, se tende a ver as tecnologias como caminhos para a redenção, a transcendência, a perfeição, ainda confronta-se com um ou outros casos que surgem para recordar que ainda se está sujeito ao inesperado. Um imaginário estruturador da sociedade, mas que se desvanece, ao menos por alguns instantes, ao menor distúrbio da realidade. 


\section{Referências}

BATAILLE, Georges. O Erotismo. Porto Alegre: LP\&M, 1987.

BAUDRILLARD, Jean. A Transparência do Mal: ensaios sobre os fenômenos extremos.

São Paulo: Papirus, 1990.

. Da Sedução. São Paulo: Papirus, 1991.

. Le Pacte de lucidité ou l'intelligence du Mal. Paris : Galilée, 2004.

O crime perfeito. Lisboa: Relógio D’água, 1996.

Tela Total: mito-ironias do virtual e da imagem. Porto Alegre: Sulina, 2002.

. Simulacros e Simulação. Lisboa: Relógio D’água, 1991.

LE BRETON, David. Adeus ao corpo: Antropologia e Sociedade. Campinas:

Papirus, 2003.

NICKEL, Barbara; TONIN, Juliana. Sexo ciborgue: uma união inusitada entre o desejo da carne e a racionalidade cibernética. In: VIII Seminário Internacional da Comunicação, GT Tecnologias do Imaginário e Cibercultura, Porto Alegre, 2005, CD-ROM

SANTOS, Francisco Coelho dos. Revelações da carne: corpo e sexualidade nas redes sociotécnicas. In: Encontro Nacional da Associação Nacional dos Programas de Pós-Graduação em Comunicação, 12, 2003, Rio de Janeiro. Anais... Rio de Janeiro, 2003. Disponível em: http://www.comunica.unisinos.br/tics/?page=textos2003. (Último acesso em: 15/9/2005.)

SFEZ, Lucien. A saúde perfeita: crítica de uma nova utopia. São Paulo: Loyola, 1996.

SIBILIA, Paula. O bisturi de sotware: ou como fazer um "corpo belo" virtualizando a carne impura? In: Encontro Nacional da Associação Nacional dos Programas de Pós-Graduação em Comunicação, 14, 2005, Niterói. Anais... Niterói, 2005. Disponível em: http://www.comunica.unisinos.br/tics/?page=textos2005. (Último acesso em: 15/9/2005.)

SPRINGER, Claudia. Electronic eros: bodies and desire in the posindustrial age. Austin: University of Texas, 1996. 